\title{
CRISIS DEL CELULOIDE: CRITERIOS DE EXPOSICIÓN EN EL PASO DEL FOTOQUIMICO AL DIGITAL EN EL CINE DE HOLLYWOOD
}

\author{
Film's crisis: Exposure criteria in the evolution from \\ photochemical to digital image capture in contemporary \\ Hollywood cinema
}

\section{Nadia McGowan y Luis Deltell}
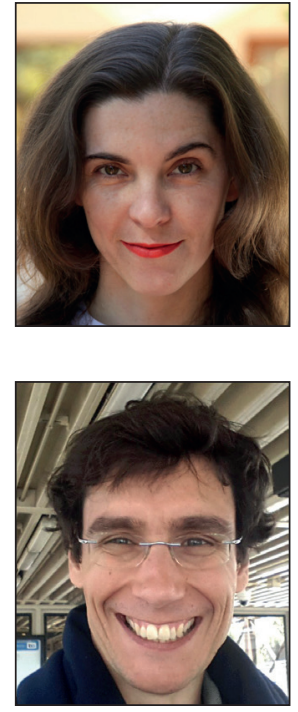

Nadia McGowan, estudiante de doctorado en la Universidad Complutense de Madrid, es profesora del Departamento de Radio y Televisión de la Notre Dame University Louaize en Líbano donde imparte las asignaturas de Iluminación y de Realización de series. Ha trabajado en el sector audiovisual como cámara y colabora con la revista técnica cinematográfica Cameraman. Es miembro del grupo de investigación UCM-Santander "Pensamiento y representación literaria y artística digital ante la crisis de Europa y en el Mediterráneo" (PR26/16-6B-1).

http://orcid.org/0000-0003-3584-4767

nmcgowan@ucm.es

Luis Deltell es profesor contratado doctor de la Facultad de Ciencias de la Información de la Universidad Complutense de Madrid, donde imparte la asignatura de Comunicación digital. Director de cine y miembro del proyecto de investigación UCM-Santander "Pensamiento y representación literaria y artística digital ante la crisis de Europa y en el Mediterráneo" (PR26/16-6B-1).

http://orcid.org/0000-0002-5230-1409

Ideltell@ccinf.ucm.es

Universidad Complutense de Madrid, Facultad de Ciencias de la Información Avenida Complutense S/N. 28040 Madrid, España

\section{Resumen}

La crisis en el modelo de producción cinematográfica, con su cambio de paradigma hacia el cine digital, parece implicar también una revolución estética. En la presente investigación cuantitativa se indaga sobre la interrelación entre exposición como valor estético y la implementación del internegativo y capturas digitales, para determinar criterios cuantitativos relativos a la adopción de estas tecnologías. Para ello se ha extraído un fotograma cada 14 segundos de 264 largometrajes producidos en Hollywood y se han monitorizado sus niveles de iluminación medios y de iluminación en el rango de bajas luces. Con esta información, se busca relacionar la respuesta a la luz de los diferentes métodos de captación y tratamiento de la imagen. Además, se estudia su adopción en la industria de Hollywood, en la que la reproducción de las sombras se considera un factor crucial.

\section{Palabras clave}

Cine; Cinematografía digital; Iluminación; Celuloide; Internegativo digital; Postproducción; Crisis; Etalonaje.

\section{Abstract}

The crisis affecting film production models and its paradigm shift towards digital seems to also imply an esthetic revolution. In this quantitative research we aim to explore the interrelation between exposure as an esthetic value and the implementation of digital internegative and capture in order to determine quantitative criteria relative to the adoption of these technologies. In order to do this, one frame every fourteen seconds was extracted out of 264 feature films produced in Hollywood, and their average light levels and low-light range levels were quantitatively analyzed. With this information, we aimed to relate different image-capture and image-treatment methods to their implementation in the Hollywood film-making industry and consider low-light reproduction a crucial factor.

\section{Keywords}

Cinema; Digital cinematography; Lighting; Film; Digital internegative; Postproduction; Crisis; Color grading. 
McGowan, Nadia; Deltell, Luis (2017). "Crisis del celuloide: criterios de exposición en el paso del fotoquímico al digital en el cine de Hollywood". El profesional de la información, v. 26, n. 6, pp. 1149-1158.

https://doi.org/10.3145/epi.2017.nov.14

\section{Introducción: la permanencia o la extinción del celuloide}

La industria cinematográfica es una de las más afectadas por la crisis económica y por los cambios tecnológicos. Su mutación es tan grande que puede devenir en un espectáculo en el cual el celuloide y lo fílmico dejen de ser lo esencial. Algunos directores como Víctor Erice (2005) anuncian su muerte, e investigadores como Quintana (2011) o Manovich (2005) presentan la idea de un postcine, en el que todos los contenidos audiovisuales serán digitales y su exhibición en salas será anecdótica. La transformación parece más evidente en países con economías menores, donde la industria cinematográfica y la exhibición en salas están seriamente amenazadas; sirva de ejemplo España (Deltell; García-Fernández, 2013). Sin embargo, en Estados Unidos y en especial en la producción de Hollywood, es donde probablemente se decidirá el mantenimiento o la extinción del celuloide como soporte básico del cine.

Autores como Flaxton (2011) o Fussfeld-Cohen (2014) hablan de "revolución estética" tras la llegada de las tecnologías digitales:

"Actualmente muchas evidencias sustentan la hipótesis de que los aspectos técnicos y prácticos de la producción fílmica digital transforman la estética de las películas de manera que cambian las prácticas expresivas de las manifestaciones cinematográficas" (Fussfeld-Cohen, 2014, p. 48).

Otros, como Turnock (2012), buscan aspectos en común entre estos cambios y estéticas anteriores.

Creemos que merece la pena cuestionarse si la tecnología digital ha modificado la imagen de la obra cinematográfica y, de haberlo hecho, en qué manera. John Belton (2002) asegura que se trata de una "falsa revolución" porque el producto consumido por el espectador sigue siendo el mismo. Stephen Prince (2004) cree que el paso al digital cambia el significado del cine porque:

"La información en la luz -su gama, contraste, valor de negros, realces, claridad y filtración- y las estrategias compositivas y movimientos necesarios de la cámara para ejecutar los planos, son percibidas diferentemente por la película y el vídeo" (Prince, 2004, p. 32).

Los cambios en los métodos de producción han afectado especialmente a la dirección de fotografía, con nuevos soportes de captación de imagen y procesos de postproducción. Aunque en la legislación de muchos países la figura del director de fotografía está reconocida como coautor de la obra cinematográfica (McGowan, 2016), los estudios académicos sobre esta profesión y sobre su técnica son escasos en general. Existen importantes textos que la abordan desde una perspectiva estética, como Loiseleux (2005) y Revault (2003), o histórica, como Llinàs-Mascaró (1989) y
Keating (2014). Sin embargo, muy pocos emprenden una investigación rigurosa sobre aspectos técnicos, aunque es precisamente la técnica lo que diferencia de forma radical al director de fotografía de otros oficios y autores cinematográficos.

Nuestra investigación se plantea desde una perspectiva cuantitativa, el análisis de algunos de los parámetros técnicos más importantes de la industria fílmica actual: las implicaciones del uso de negativo, internegativo y etalonaje ${ }^{1}$ digitales en la estética de los largometrajes.

El principal asesor y el responsable de imagen de un largometraje es el director de fotografía. Una de sus tareas básicas consiste precisamente en determinar la exposición de la película, es decir, la cantidad de luz y los valores de negro que tendrá la imagen. Otra decisión clave es el uso de una cámara digital o de una cámara de celuloide. Esta apuesta resulta básica para conseguir unos efectos y aspectos determinados. Así, el director de fotografía deberá consensuar con el realizador sobre las intenciones estéticas y emocionales que se buscan.

La fiabilidad de la cámara de celuloide parece superior ya que se han mencionado con frecuencia los problemas en la exposición y las deficiencias en el rango dinámico de las cámaras digitales, incluso de las más actuales (Gray, 2015). Sin embargo en la actualidad la conversión al cine digital resulta evidente y en algunos países se da por concluida.

Autores como Àngel Quintana (2011) o Manovich (2005) creen que se trata de una revolución estética y temática que posibilita una nueva forma de narración. El abaratamiento resulta significativo; de hecho, las industrias menores como la española se encuentran casi obligadas a grabar en digital ya que en sus países no quedan laboratorios o si persiste alguno es en condiciones precarias, como indican Gubbins (2011) y Peiró (2013).

En esta investigación proponemos estudiar el cambio hacia lo digital no por motivos económicos o de precariedad de presupuestos, sino por una decisión técnica y fotográfica; es decir, por una cuestión visual y estética o poética, en palabras de Bordwell y Thompson (2007). Por eso escogemos la única industria que puede permitirse el rodaje en celuloide sin que este modifique sustancialmente el presupuesto final del filme: el análisis se centra en las diferencias de uso entre la fotografía y etalonaje digitales y analógicos en la industria de Hollywood.

Para abordar esta investigación debemos situarnos necesariamente en una perspectiva científica y cuantitativa. Nuestro análisis no valora la implicación cualitativa y económica de los cambios fímicos sino el valor cuantitativo de la exposición, la latitud, los valores de rango y el negro absoluto del filme. Este proyecto que presentamos se acerca en parte a los modelos propuestos por David Bordwell (2002), 
que analizó de manera cuantitativa los planos y los recursos técnicos en 400 largometrajes estadounidenses. Pero también a los modelos que diseñó King para el estudio de las representaciones de los héroes estadounidenses (1999), e incluso los esbozados en los años setenta por Salt (1974). Si bien es cierto, como recoge Méndez-Anchuste (2016), que algunos de estos autores han ido cambiando y modificando sus postulados con los años, todos ellos abogan por valorar los datos cuantitativos.

Desde hace casi dos décadas, coincidiendo con la aparición de nuevos recursos digitales, han aumentado los estudios concernientes a la investigación cuantitativa sobre aspectos propios de la luz cinematográfica. El equipo de análisis de Adams (Adams; Dorai; Venkatesh, 2000) propuso un nuevo modelo cuantitativo para la extracción automática de elementos expresivos del cine. En el ámbito anglosajón destacan los trabajos de Buckland (2008) y los encabezados por el grupo de investigación de Cutting (Cutting; DeLong; Brunik 2011). En España existen algunas propuestas como la ofrecida por Cortés (2012), pero los estudios de monitorización de parámetros son aún minoritarios en las ciencias de la comunicación centradas en el cine.

\section{La implantación del cine digital no supo- ne una crisis de representación visual}

Los dos momentos claves en la creación de la imagen que nos atañen en esta investigación son el de captación y el de su posterior tratamiento en postproducción (etalonaje y otros). La adquisición de la imagen puede realizarse por medios fotoquímicos (celuloide), que representan el modelo tradicional de producción o digitales que suponen una ruptura y quiebra. El término anglosajón color grading, conocido en castellano como etalonaje, es la manipulación de los valores cromáticos de la imagen rodada. Está técnica podría realizarse de forma tradicional o fotoquímica mediante laboratorios, pero hoy en día está prácticamente en desuso. Sin embargo, se ha impuesto en la industria la variante digital, el llamado digital intermediate o internegativo digital. Este proceso consiste en el escaneo de la imagen fotoquímica para su tratamiento digital, o en el retoque del máster de una obra adquirida digitalmente (Belton, 2008).

Por tanto, nuestra investigación cuantitativa no se centra en indagar los motivos económicos de la crisis del celuloide y del cine filmado, sino en estudiar las diferencias de valores de la luz cinematográfica producidas en las películas de Hollywood de gran presupuesto según se hayan filmado con celuloide o grabado en soporte digital.

\section{Objetivos}

Esta investigación propone analizar aspectos cuantitativos de la fotografía del cine con relación a la exposición, al valor de negro y al rango dinámico entre películas filmadas en celuloide y otras rodadas en soporte digital. Para evitar que las cuestiones económicas fuesen las que obligaron a los cineastas a seleccionar el sistema digital, hemos optado por estudiar la industria de Hollywood. Nuestra pregunta inicial es ¿por qué el cine de Hollywood, si dispone de dinero sufi- ciente para filmar en celuloide, ha decido grabar en digital y usa como base el internegativo digital? Para ello se monitorizan 264 largometrajes.

El corpus de trabajo es una selección de películas representativas de reconocido valor artístico y de gran aceptación de público. Se han seleccionado las diez películas más taquilleras entre los años 2000 y 2015 según datos de Box Office Mojo. Para no sesgar los largometrajes con mayor calidad estética fotográfica, se han incluido las obras nominadas y ganadoras en los Premios Oscar de la Academy of Motion Picture Arts and Sciences en las categorías de mejor película, mejor dirección y mejor cinematografía. Se han eliminado los largometrajes de animación, dado que su método de producción es ajeno a lo que aquí se estudian. También se excluyen producciones mixtas donde una mayoría de sus personajes son generados por ordenador, como Dinosaurio (Zondag; Leighton, 2000) y Los pitufos (Gosnell, 2011). Esto nos lleva a un total de 264 películas.

Planteamos los siguientes objetivos de trabajo:

a) Extraer un fotograma cada 14 segundos de las 264 películas seleccionadas, con el programa VirtualDub. Presentamos la monitorización realizada a 300 (Snyder, 2007) (imagen 1), Carol (Haynes, 2015) (imagen 2), Slumdog millionaire (Boyle, 2008) (imagen 3), Tigre y dragón (Lee, 2000) y Winter's bone (Granik, 2011).

b) Monitorizar cuáles son los valores de iluminación promedio del período y los valores por rangos, calculando la media de iluminación por imagen, su desviación estándar, mínima, máxima, moda y mediana para una profundidad de 8-bit ( 256 valores, de 0 a 255 donde el 0 es negro y el 255 es blanco).

c) Generar un histograma propio de cada una de las 264 películas y determinar si hay variaciones de valores lumínicos entre películas de rodaje y postproducción fotoquímica y digital.

d) Establecer el promedio de iluminación de los largometrajes seleccionados. Realizar si procede, una correlación entre diferentes valores de iluminación y equipos utilizados (digitales o tradicionales).

e) Distribución de los valores de iluminación por intervalos a partir de histogramas.

f) Establecer una cronología de estos cambios y su relación con la respuesta de estos sistemas a la luz.

Cumplir con estos objetivos nos permitirá obtener los datos cuantitativos, para entender cuál es la tendencia de uso en Hollywood. A partir de ahí, establecer cuál es el modelo de representación que se hace por medio de la imagen en celuloide o de la imagen digital.

\section{Metodología}

La presente metodología ha sido desarrollada por los autores de la investigación. Este estudio se basa en un proceso cuantitativo inspirado en los modelos de Salt y Bordwell y en los trabajos ya citados de Adams, Buckland y Cutting. Además se recurre a las nuevas posibilidades digitales para la monotorización automática de parámetros expresivos y va- 


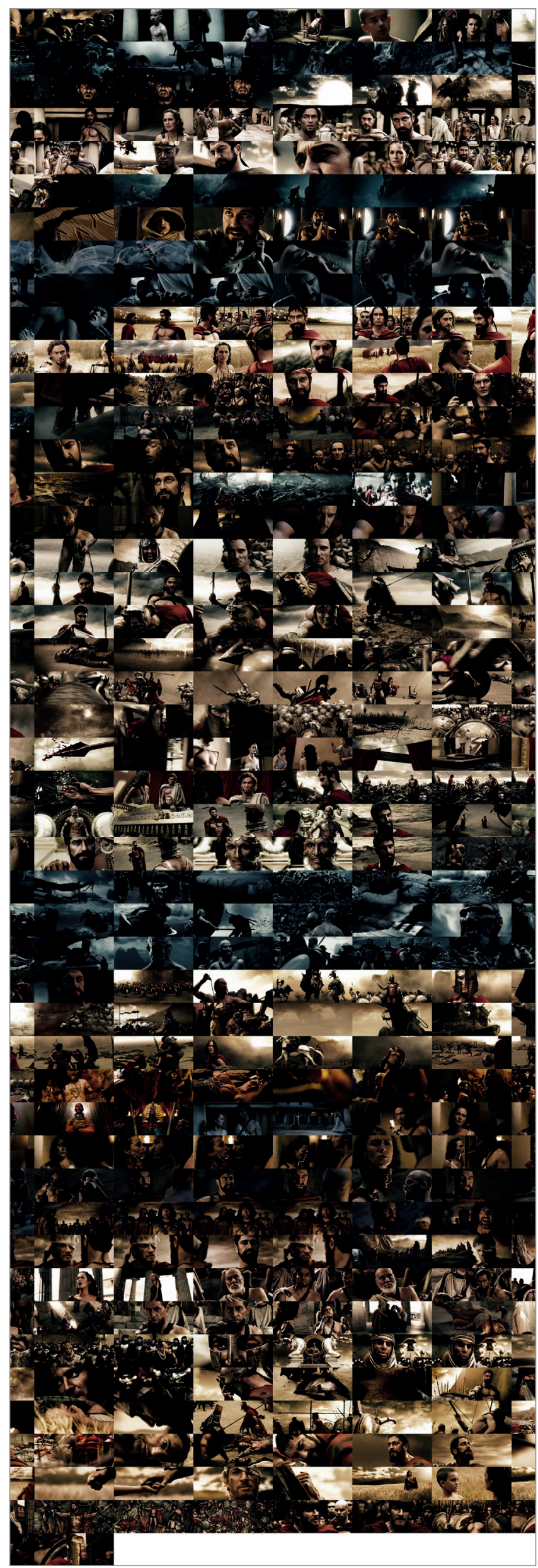

Imagen 1. Ejemplo de monitorización de 300 (Snyder, 2007) lores técnicos. De cada película se ha extraído un fotograma cada 14 segundos con el programa VirtualDub (aunque el experimento podría reproducirse con el programa FFmpeg).

Del catálogo de imágenes extraídas se han eliminado aquellas de apertura que consisten en créditos corporativos o meras infografías sin imágenes rodadas a propósito para la película o que sean parte de su narrativa. Este procedimiento se ha repetido con los créditos finales, para eliminar desvíos que generarían medir fotogramas mayoritariamente opacos. Estas imágenes, o capturas de muestreo, se han guardado en formato ${ }^{*}$.jpg, a partir de una resolución de 1080 píxeles en los casos en los que había Blu-ray disponible, y 720 píxeles en los casos en DVD.

Esta selección se ha procesado con ImageJ (Schneider; Rasband; Eliceiri, 2012), donde se han importado como una secuencia y calculado la media de iluminación por imagen, su desviación estándar, mínima, máxima, moda y mediana para una profundidad de 8-bit (256 valores, de cero a 255 donde el cero es negro y el 255 es blanco). A partir del resultado de todas las imágenes escogidas por largometraje se han calculado los promedios de cada uno. Se ha generado un histograma con la cantidad de píxeles totales por valor de iluminación.

Los valores del histograma se han distribuido en cinco bloques:

$0-50$, bajas luces;

51-101, luces medias-bajas;

102-152, medias luces;

153-203, medias-altas luces;

204-255, altas luces.

Se ha calculado el porcentaje de píxeles en cada bloque para cada película. Hemos optado por trabajar con porcentajes y no con el número de píxeles, porque así eliminamos las diferencias existentes entre Blu-ray y DVDs.

\section{Existe un asentamiento cada vez mayor del rodaje digital y del abandono de celuloide, en especial desde el período 2010-13}

Se han clasificado las películas según sistema de captura y sistema de postproducción. Esta información se ha obtenido de revistas especializadas como la American cinematographer magazine en la mayoría de los casos. La información que no quedaba cubierta por esta publicación se ha complementado por otras ediciones especializadas en cinematografía, como British cinematographer, Cameraman; y por webs como Internet movie database y ShotOnWhat?, que recogen datos técnicos de las películas.

Se ha observado que se dan muchos casos de capturas mixtas, donde se ha utilizado celuloide y digital. En estos casos, se han clasificado según el sistema de captura mayoritario. Por ejemplo, Mission impossible: Rogue nation, de Christopher McQuarrie (2015), que utilizó $35 \mathrm{~mm}$ en todas sus secuencias excepto en una subacuática, por motivos técnicos, ha sido clasificada como rodaje en celuloide. Jurassic world (2015) de Colin Trevorrow, fue rodada mayoritariamente en 


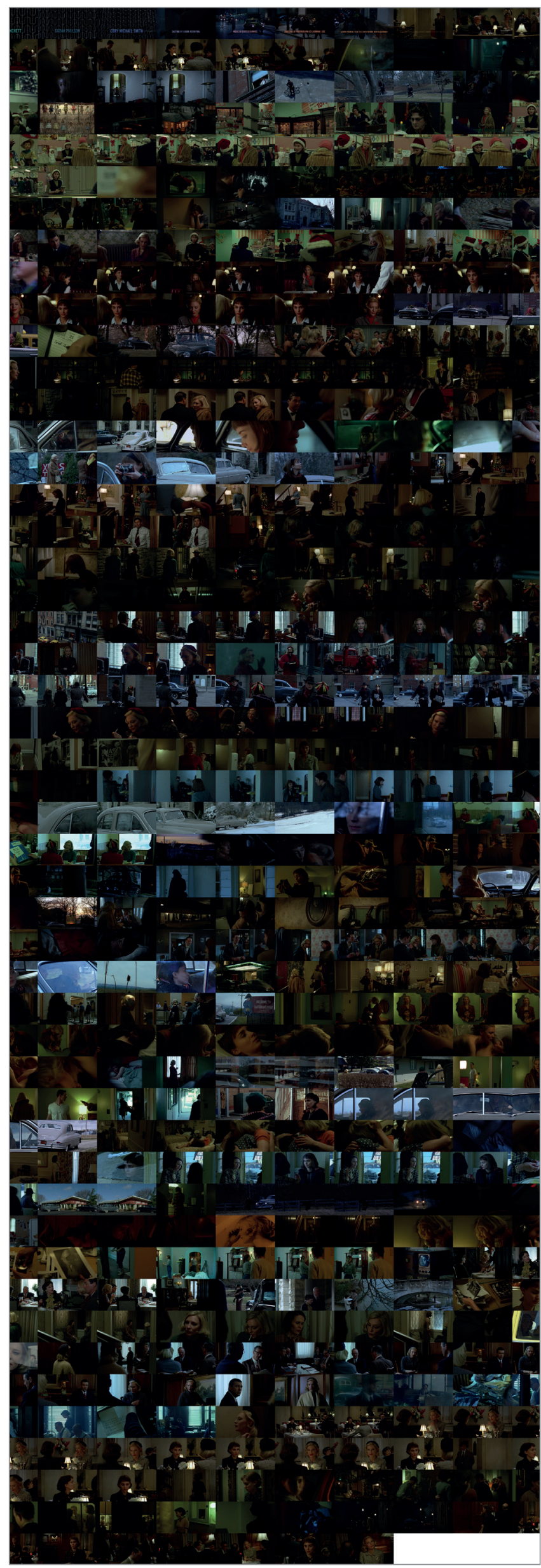

Imagen 2. Ejemplo de monitorización de Carol (Haynes, 2015)

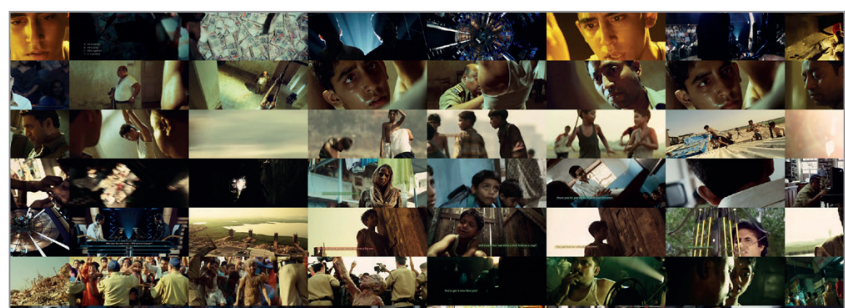

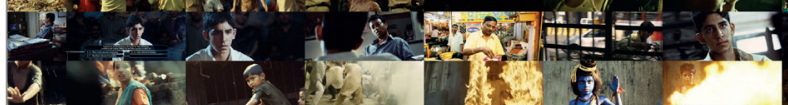

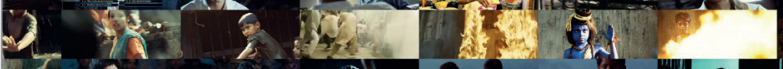

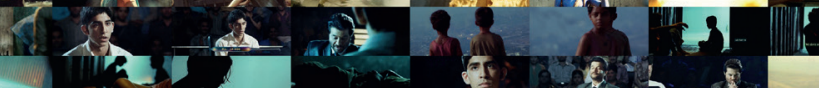

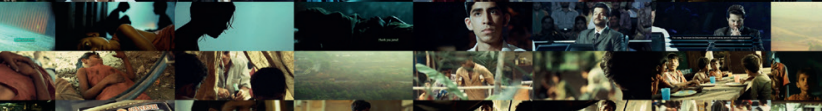

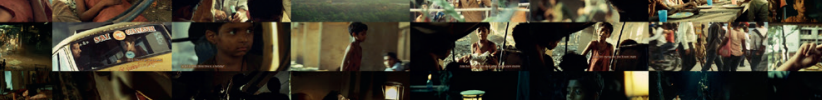
D. I

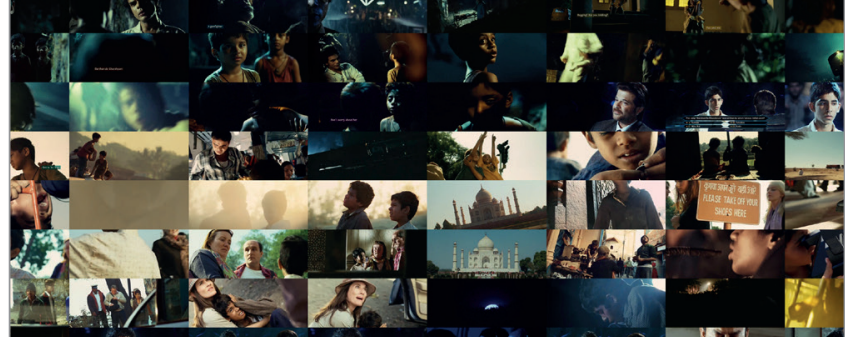

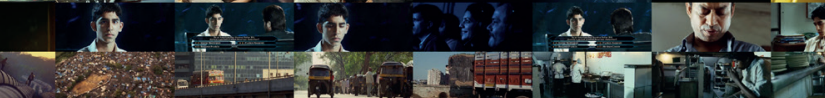

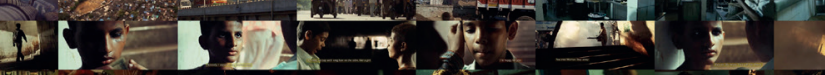

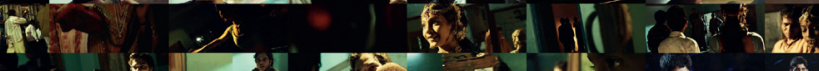

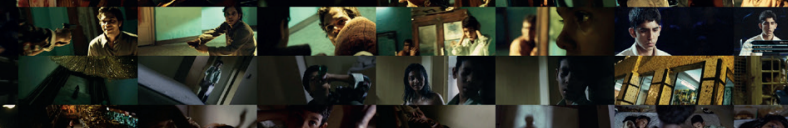

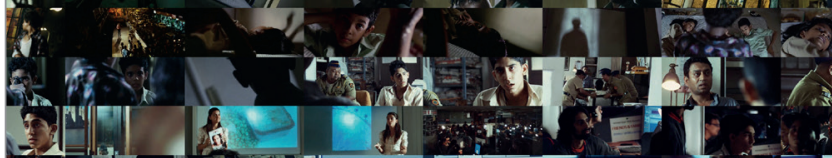

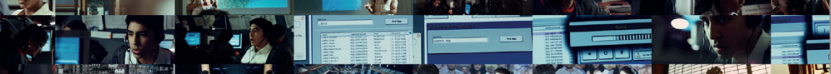

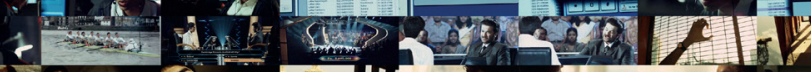
यद त N"

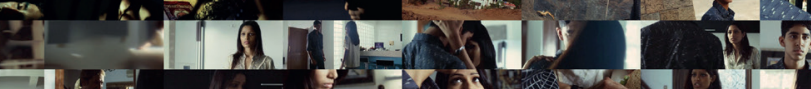

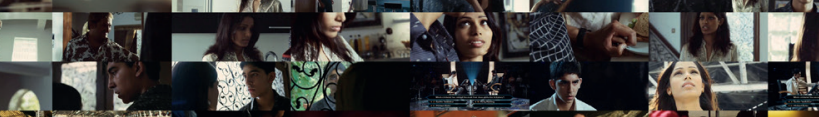
a.

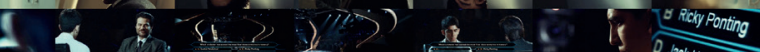

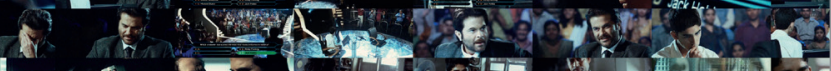

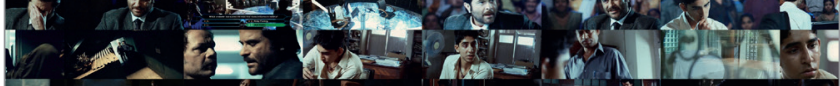

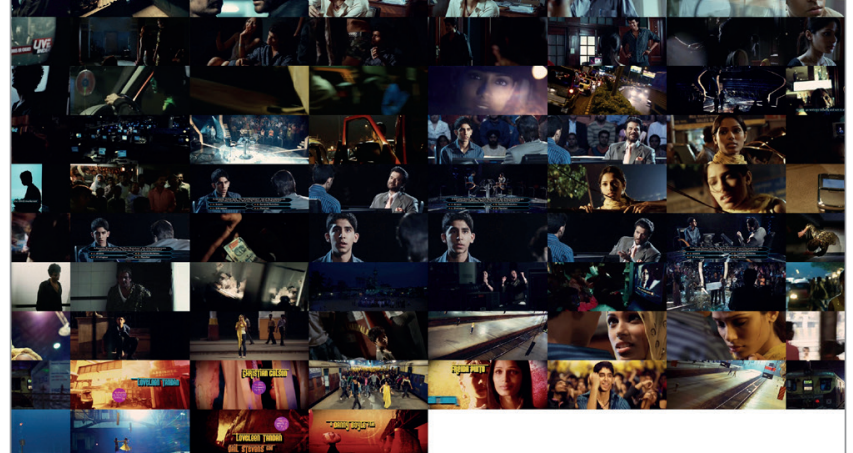
Imagen 3. Ejemplo de monitorización de Slumdog Millionaire (Boyle, 2008) 
Tabla 1. Cantidad de casos por año

\begin{tabular}{|c|c|c|c|c|c|}
\hline Año & $\begin{array}{c}\text { Rodaje } \\
\text { fotoquímico }\end{array}$ & $\begin{array}{c}\text { Rodaje } \\
\text { digital }\end{array}$ & $\begin{array}{c}\text { Posp. } \\
\text { fotoquímica }\end{array}$ & Posp. ID & $\begin{array}{c}\text { Total } \\
\text { año }\end{array}$ \\
\hline 2000 & 17 & 0 & 14 & 3 & 17 \\
\hline 2001 & 16 & 0 & 13 & 3 & 16 \\
\hline 2002 & 15 & 1 & 13 & 3 & 16 \\
\hline 2003 & 16 & 0 & 6 & 10 & 16 \\
\hline 2004 & 16 & 0 & 3 & 13 & 16 \\
\hline 2005 & 15 & 1 & 5 & 11 & 16 \\
\hline 2006 & 17 & 1 & 2 & 16 & 18 \\
\hline 2007 & 14 & 0 & 2 & 12 & 14 \\
\hline 2008 & 11 & 2 & 0 & 13 & 13 \\
\hline 2009 & 15 & 2 & 0 & 17 & 17 \\
\hline 2010 & 9 & 4 & 1 & 12 & 13 \\
\hline 2011 & 13 & 4 & 0 & 17 & 17 \\
\hline 2012 & 10 & 7 & 1 & 16 & 17 \\
\hline 2013 & 9 & 9 & 0 & 18 & 18 \\
\hline 2014 & 6 & 15 & 1 & 20 & 21 \\
\hline 2015 & 7 & 12 & 1 & 18 & 19 \\
\hline Total & 206 & 58 & 62 & 202 & 264 \\
\hline & & & & & \\
\hline
\end{tabular}

digital, pero con aproximadamente un treinta por cien de secuencias (Holben, 2015) en $65 \mathrm{~mm}$ para su exhibición en IMAX, por lo que se ha clasificado como película digital.

La postproducción de las obras se ha analizado según se usase un etalonaje fotoquímico o un etalonaje digital. Al igual que en el estudio de la captura, se ha analizado según el sistema predominante usado en este proceso. Un ejemplo: en Le scaphandre et le papillon (2008) de Julian Schnabel, se realizó un internegativo para integrar efectos digitales, pero no para etalonar, por lo que se considera postproducción fotoquímica al ser la parte digital minoritaria y sin intención de variar la iluminación de la imagen (Thomson, 2008). Del mismo modo, en The hateful eight (2015) de Quentin Tarantino, hubo un internegativo digital completo para convertir el $65 \mathrm{~mm}$ de rodaje en un $D C P^{2}$ para su proyección en salas digitales, pero el etalonaje se realizó en celuloide y mediante procesos tradicionales de laboratorio, por lo que se considera una postproducción fotoquímica.

La mutación del cine es tan grande que puede devenir en otro espectáculo en el cual el celuloide y lo fílmico deje de ser lo esencial

Todas las tablas, gráficas y capturas de muestreo son originales y han sido creadas por los autores de esta investigación.

\section{Resultados y discusión}

Para la correcta interpretación de los datos obtenidos, el primer parámetro a consultar es la cantidad de muestras por año (tabla 1). Se puede observar que no hay largometrajes rodados de forma digital en los años 2000, 2001, 2003,
Tabla 2. Promedio de iluminación por año y sistema de captura

\begin{tabular}{|l|c|c|c|}
\hline Año & Media & $\begin{array}{c}\text { Media rodaje en } \\
\text { celuloide }\end{array}$ & $\begin{array}{c}\text { Media rodaje } \\
\text { digital }\end{array}$ \\
\hline 2000 & 56,66794 & 56,66794 & - \\
\hline 2001 & 50,38669 & 50,38669 & - \\
\hline 2002 & 47,89419 & 47,21500 & 58,08200 \\
\hline 2003 & 56,00269 & 56,00269 & - \\
\hline 2004 & 58,33550 & 58,33550 & 49,44900 \\
\hline 2005 & 51,94425 & 52,11060 & 36,83500 \\
\hline 2006 & 50,95950 & 51,79035 & - \\
\hline 2007 & 56,52443 & 56,52443 & 56,35700 \\
\hline 2008 & 54,80692 & 54,52509 & 69,64450 \\
\hline 2009 & 53,11582 & 50,91200 & 51,98625 \\
\hline 2010 & 49,41362 & 48,27022 & 52,12750 \\
\hline 2011 & 52,60018 & 52,74562 & 50,54414 \\
\hline 2012 & 48,26247 & 46,66530 & 52,09511 \\
\hline 2013 & 52,85878 & 53,62244 & 54,61560 \\
\hline 2014 & 54,19386 & 53,13950 & 58,59767 \\
\hline 2015 & 55,65800 & 50,61857 & 54647 \\
\hline Media & 53,12316 & 52,75057 & - \\
\hline total & & & \\
\hline
\end{tabular}

2004 y 2007. En esos años no hubo ninguna película que cumpliera todos los criterios de selección, es decir que se filmara en soporte digital completamente. Son años previos a la implementación en este sector de dicho formato de captación. De manera análoga, no hay casos de postproducción fotoquímica en los años 2008, 2009, 2011 y 2013; todas las películas de dichos años son etalonadas mediante internegativo digital.

En la tabla 2 se detallan los resultados del valor promedio de iluminación según el sistema de captación utilizado. Dada la escasa diferencia entre los rangos de celuloide y de digital, con 1,6959 puntos de diferencia entre sí, se puede concluir que el formato de captación no afecta a la iluminación como rasgo estético de la imagen, aunque las películas digitales sean ligeramente más luminosas.

En el promedio de iluminación según el sistema de postproducción tampoco se observan diferencias reseñables. Los resultados pueden consultarse en la tabla 3.

Hay una desviación de 2,33 puntos entre las películas de postproducción digital y fotoquímica, donde las películas con internegativo digital son ligeramente más luminosas. En los años en los que el muestro es menor se presentan las diferencias más marcadas entre sistemas de tratamiento de la imagen. En 2006 y 2007 sólo se dan dos casos de películas etalonadas fotoquímicamente, y en 2010, 2012, 2014 y 2015 hay únicamente un caso por año. Con tan pocos ejemplos no se puede establecer una tendencia general.

Estos resultados permiten descartar cambios en los parámetros de la iluminación causados por la implementación de tecnologías digitales en captación y etalonaje. Además, podemos observar que se da una continuidad estética a lo largo del período, donde el valor mínimo promedio es de 
Tabla 3. Promedio de iluminación por año y sistema de postproducción

\begin{tabular}{|l|c|c|c|}
\hline Año & Media & $\begin{array}{c}\text { Media post. } \\
\text { fotoquímica }\end{array}$ & $\begin{array}{c}\text { Media interne- } \\
\text { gativo digital }\end{array}$ \\
\hline 2000 & 56,66794 & 55,35207 & 62,80867 \\
\hline 2001 & 50,38669 & 50,40177 & 50,32133 \\
\hline 2002 & 47,89419 & 46,30800 & 54,76767 \\
\hline 2003 & 56,00269 & 48,00267 & 60,80270 \\
\hline 2004 & 58,33550 & 53,46233 & 59,46008 \\
\hline 2005 & 51,94425 & 54,24820 & 50,89700 \\
\hline 2006 & 50,95950 & 60,87900 & 49,71956 \\
\hline 2007 & 56,52443 & 71,65850 & 54,00208 \\
\hline 2008 & 54,80692 & & 54,80692 \\
\hline 2009 & 53,11582 & & 53,11582 \\
\hline 2010 & 49,41362 & 45,67600 & 49,72508 \\
\hline 2011 & 52,60018 & & 52,60018 \\
\hline 2012 & 48,26247 & 30,74200 & 49,35750 \\
\hline 2013 & 52,85878 & & 52,85878 \\
\hline 2014 & 54,19386 & 54,17500 & 54,19480 \\
\hline 2015 & 55,65800 & 35,37200 & 56,78500 \\
\hline Media & 53,12316 & 51,33613 & 53,67165 \\
\hline total & & & \\
\hline
\end{tabular}

47,894 y el máximo de 56,667 . No parece haber una tendencia al alza ni a la baja, aunque para determinar este dato con certeza sería recomendable una muestra mayor en el tiempo y en número de obras.

A partir de estos datos intentaremos determinar si existe una continuidad en los modelos de iluminación. Para ello analizamos los histogramas de las películas, concretamente los de los píxeles que pertenecen a los que hemos clasificado como bajas luces (valores entre 0 y 50 ) puesto que son los que contienen la gran mayoría de los píxeles de las imágenes de estas películas. Usando esta información argumentaremos cómo la reproducción de las bajas luces puede ser clave para explicar la evolución en los estándares de trabajo en la industria hollywoodiense.

Dividiremos esta evolución en las siguientes fases:

a) Fase de experimentación: pocos casos (0-3 por año), porcentaje de tonos oscuro con gran variación respecto a la media del año y total del período.

b) Fase de asentamiento: minoría de casos y/o porcentaje de bajas luces con sustancial variación respecto a la media de ese mismo año ( $\geq 3$ puntos) y del total del período ( $\geq 5$ puntos).

c) Fase de consolidación: mayoría de casos y cercanas a la media del año ( $<3$ puntos) y del período ( $<5$ puntos).

Estos resultados se cotejan con la media del período completo de estudio para compararlos con la estética global. Así observamos la variación estética de las películas digitales con las de celuloide en un mismo año.

Los datos del porcentaje de píxeles correspondientes al rango de bajas luces (0-50) pueden consultarse en la tabla 4. En
Tabla 4. Porcentaje de píxeles de bajas luces por año (\%)

\begin{tabular}{|c|c|c|c|c|c|}
\hline Año & $\begin{array}{l}\text { Medias } \\
\text { totales }\end{array}$ & $\begin{array}{l}\text { Rodaje } \\
\text { fotoquí- } \\
\text { mico }\end{array}$ & $\begin{array}{l}\text { Rodaje } \\
\text { digital }\end{array}$ & $\begin{array}{l}\text { Post. } \\
\text { fotoquí- } \\
\text { mica }\end{array}$ & $\begin{array}{l}\text { Post. } \\
\text { digital }\end{array}$ \\
\hline 2000 & 57,996 & 58,00 & & 58,63 & 55,02 \\
\hline 2001 & 63,420 & 63,42 & & 63,59 & 62,70 \\
\hline 2002 & 64,955 & 65,38 & 58,55 & 66,19 & 59,59 \\
\hline 2003 & 59,646 & 59,65 & & 66,06 & 55,80 \\
\hline 2004 & 56,823 & 56,82 & & 59,16 & 56,28 \\
\hline 2005 & 63,470 & 63,24 & 66,90 & 61,40 & 64,41 \\
\hline 2006 & 64,319 & 63,70 & 74,84 & 55,09 & 65,47 \\
\hline 2007 & 60,958 & 60,96 & & 48,74 & 62,99 \\
\hline 2008 & 61,792 & 61,62 & 62,75 & & 61,79 \\
\hline 2009 & 62,968 & 64,61 & 50,63 & & 62,97 \\
\hline 2010 & 64,266 & 64,99 & 62,64 & 67,36 & 64,01 \\
\hline 2011 & 61,936 & 61,38 & 63,75 & & 61,94 \\
\hline 2012 & 66,652 & 67,69 & 65,17 & 79,59 & 65,84 \\
\hline 2013 & 62,955 & 62,32 & 63,59 & & 62,96 \\
\hline 2014 & 60,698 & 59,53 & 61,09 & 62,65 & 60,60 \\
\hline 2015 & 60,425 & 66,10 & 57,11 & 81,25 & 59,27 \\
\hline Total & 61,820 & 62,23 & 61,43 & 62,70 & 61,86 \\
\hline
\end{tabular}

ella desglosamos, de todas las películas analizadas en ese año, qué porcentaje de píxeles corresponde a bajas luces de media y según sistema de captación y etalonaje. Un valor más alto implica una mayor cantidad de bajas luces, pero esto no necesariamente implica una película que se perciba como más oscura. Para ello será necesario tener en cuenta la distribución de medias y altas luces. Una imagen de alto contraste, como por ejemplo un exterior día, puede tener sombras muy densas en gran parte del encuadre, pero una pequeña porción de altas luces y los elementos principales del fotograma bien expuestos o ligeramente sobreexpuestos, pueden dar la sensación de una imagen luminosa. Este aspecto es relevante dada la diferente reproducción de bajas y altas luces en ambos formatos, donde se considera que el fotoquímico trabaja mejor con altas luces y el digital con bajas, por lo que equiparar la reproducción de éstas se hace especialmente relevante (Prince, 2004).

\section{La implementación del soporte y la postproducción digitales en la industria cinematográfica no suponen una ruptura en los valores y rangos fotográficos medios}

En el gráfico 1 se presentan los resultados contextualizados junto con el número de casos por temporada.

Se podría considerar que el período de experimentación del internegativo digital comprendió los años 2000 a 2002. En estos años hay sólo tres películas que utilizan el internegativo digital completo cada año. Las bajas luces difieren de la media de su año hasta un máximo de 5,36 puntos en 2002 


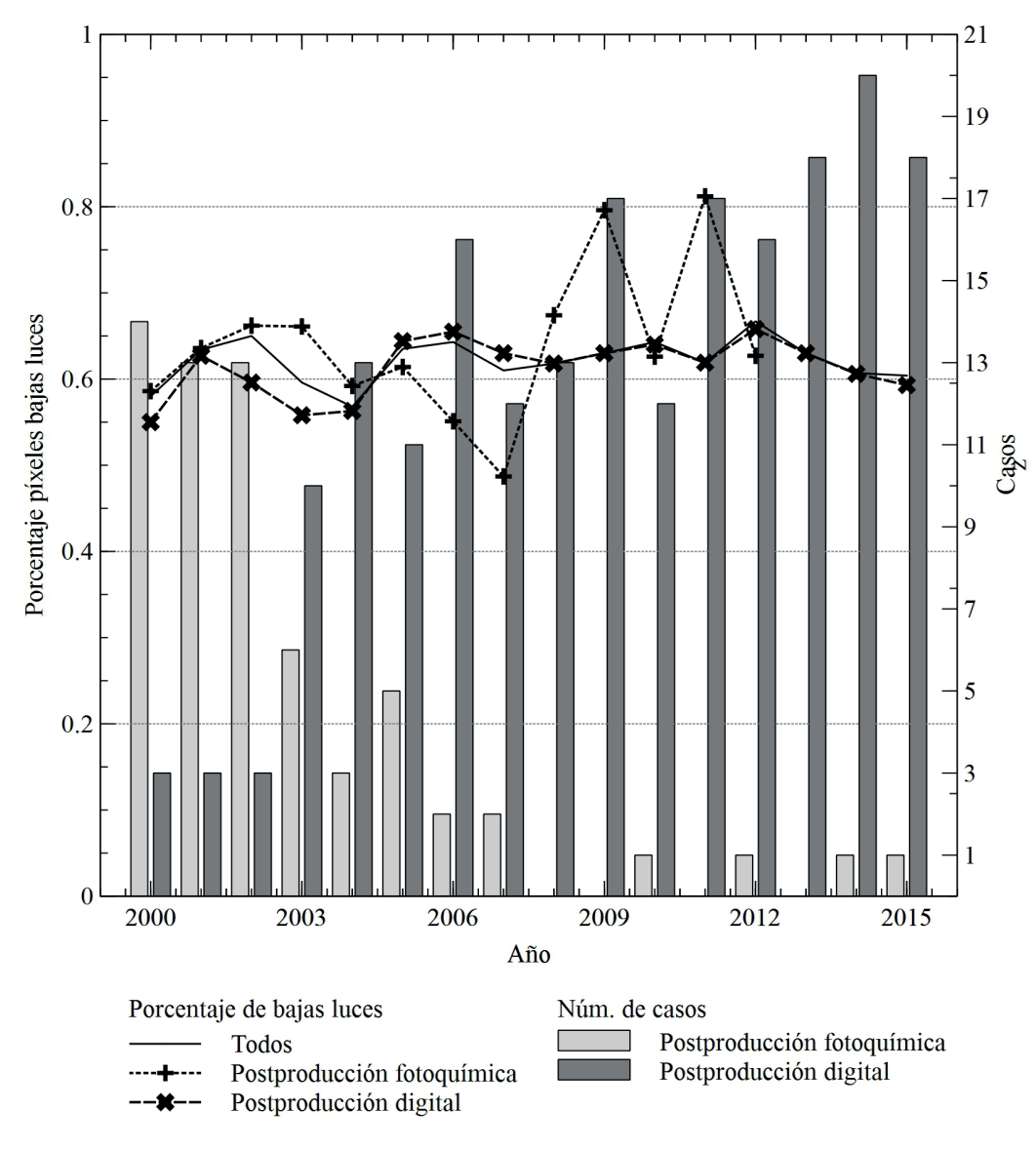

Gráfico 1. Porcentaje de píxeles en bajas luces por sistema de postproducción y número de casos, por año

(59,59\% frente a $64,95 \%$ de media ese año). Respecto a la media para el período total de estudio, la máxima variación está en 6,80 puntos en 2000 (55,02\% frente a 61,82\%). Con el criterio de número de casos ya podríamos asumir que estos años son de iniciación, pero la variabilidad en la exposición refuerza esta clasificación.

La fase de asentamiento la situamos en 2003 y 2004 . En estos dos años las películas con internegativo digital superan a las que siguen un proceso fotoquímico. En 2003 tenemos diez películas con postproducción digital frente a seis fotoquímicas y una proporción de trece frente a tres en el año siguiente. Sin embargo, se dan diferencias de exposición considerables. El límite de una variación de tres puntos respecto a la media de cada año se cumple en 2003 , con 3,84 puntos, pero esta disminuye a 0,54 en 2004. No obstante, la diferencia con la media total del período es de 6,02 y 5,54 puntos. Con estos datos se puede hablar de asentamiento hasta el inicio de una nueva fase en el año siguiente.

De 2005 en adelante se consolida el internegativo digital como proceso de etalonaje, con una mayoría de películas utilizando un proceso digital hasta incluso la práctica desaparición del fotoquímico a partir de 2007. La variación con respecto a la media de su temporada es inferior a tres puntos en todos los casos, con una máxima de 2,04 puntos en 2007. Las medias respecto a la del período de estudio difieren en menos de cinco puntos en todos los casos, lo que encaja con el criterio establecido.

La captura digital se completa posteriormente con en el etalonaje digital. En el gráfico 2 pueden observarse los datos de casos y porcentajes de píxeles de bajas luces por año ya reflejados en las tablas 1 y 4 respectivamente.

Para el rodaje digital, la fase de experimentación la situaríamos entre 2000 y 2009: hasta 2009 se ruedan como máximo dos películas en digital por año, en alguna temporada no se filma ninguna, y su número no crece hasta 2010, cuando hay 4 ejemplos digitales frente a 9 en celuloide. Respecto a los niveles de iluminación en bajas luces, la variación máxima respecto a la media de cada año se da en 2009, donde encontramos una variación en el porcentaje de bajas luces respecto a la media de ese mismo año de 12,33 puntos y 11,19 puntos respecto a la media total del período. Dada la escasez de casos, con un máximo de dos por año en 2008 y 2009, se consideran observaciones demasiado puntuales y casos experimentales para la industria.

La fase de asentamiento de la captación digital la situamos entre 2010 y 2013, donde el rodaje digital llega a igualar al realizado en celuloide. La variación respecto a la media del año se sitúa en el 1,65 puntos en 2010, 1,85 puntos en 2011, 1,48 puntos en 2012, y 0,63 puntos en 2013, por debajo de los 3 puntos establecidos como variación mínima. El rodaje digital presenta una variación de 0,82 puntos en 2010 , 1,93 puntos en 2011, 3,35 puntos en 2012 y 1,77 puntos en 2013 frente a la media del período (61,82\%). Sin embargo, estéticamente los datos son similares en cuanto a bajas luces.

\section{Los directores de fotografía manejan el soporte digital como una continuidad visual de lo aplicado previamente con celuloide}

La fase de consolidación pertenece a 2014 y 2015, donde hay mayoría de casos de captura digital ( 15 frente a 6 en 2014 y 12 frente a 8 en 2015). La diferencia entre la media del año es de 1,56 puntos en 2014 y 0,39 puntos en 2015. Respecto a la media total, la variación es de 0,73 puntos en 2014 y 4,70 puntos en 2015. Con estos datos se observa la consolidación de esta tecnología e incluso se puede aventurar que el soporte digital se impondrá en la industria de Hollywood. 


\section{Conclusiones}

Los datos obtenidos parecen negar la idea extendida de que la crisis del celuloide ha generado una revolución visual profunda y un cambio en los parámetros expresivos de la iluminación. Todo lo contrario, la implementación del soporte y la postproducción digitales en la industria cinematográfica, al menos respecto a iluminación, no suponen una ruptura en los valores y rangos fotográficos medios. Los resultados indican la continuidad estética más que un cambio de paradigma visual. El uso de nuevos equipos y de la nueva tecnología parecen vinculados a esta continuidad estética.

Además, parece evidente que existe un asentamiento cada vez mayor del rodaje digital y del abandono del celuloide, en especial desde el período 2010-13 y su posterior consolidación en las siguientes temporadas (20142015). Sin embargo esta revolución en la producción o crisis tecnológica no conllevaba una modificación sustancial de la exposición. La mayoría de los rangos y valores monitorizados muestran una gran continuidad entre las 264 películas estudiadas.

Por último, el celuloide se mantiene como soporte en rodajes y obras importantes. Algo que diferencia aún a la industria de Hollywood de otras menores como algunas europeas o las latinoamericanas.

\section{Los resultados indican la continuidad es- tética más que un cambio de paradigma visual}

Estos resultados permiten comprender mejor la adopción de las nuevas tecnologías y el porqué de su desarrollo. El caso del análisis de las 264 películas de Hollywood monitorizadas muestra que los directores de fotografía manejan el soporte digital en continuidad con la tradición visual del celuloide, no se experimenta una crisis o ruptura estética. El cambio tecnológico, al menos en las obras estudiadas, no se corresponde con una ruptura de los parámetros visuales sino con un nuevo sistema de producción y postproducción que pretende emular los resultados previos que se lograban con el celuloide.

\section{Notas}

1. Etalonaje: proceso de laboratorio cinematográfico para igualar el color, la luminosidad y el contraste de los planos que forman las secuencias de una película de cine.
2. Del inglés digital cinema package, un compendio de archivos digitales utilizados para la proyección digital cinematográfica.

\section{Agradecimientos}

Este artículo es fruto de una investigación del proyecto UCM-Santander "Pensamiento y representación literaria y artística digital ante la crisis de Europa y en el Mediterráneo" (PR26/16-6B-1).

\section{Referencias}

Adams, Brett; Dorai, Chitra; Venkatesh, Svetha (2000). "Towards automatic extraction of expressive elements from motion pictures: Tempo". En: IEEE Intl conf on multimedia and expo, New York, 30 July-2 Aug., v. 2, pp. 641-645.

https://goo.gl/Pwkfyx

https://doi.org/10.1109/ICME.2000.871444

Belton, John (2002). "Digital cinema: A false revolution". October, n. 100, pp. 99-114.

http://english.rutgers.edu/images/documents/faculty/ belton-ja-2002a.pdf

Belton, John (2008). "Painting by the numbers: the digital intermediate". Film quarterly, v. 61, n. 3, pp. 58-65.

http://www.academia.edu/12311650/Painting_by_the_ Numbers_the_Digital_Intermediate 
https://doi.org/10.1525/fq.2008.61.3.58

Bordwell, David (2002). "Intensified continuity visual style in contemporary American film". Film quarterly, v. 55, n.3, pp. 16-28.

https://cinecdoque.files.wordpress.com/2015/03/bordwellintensified-continuity.pdf

https://doi.org/10.1525/fq.2002.55.3.16

Bordwell, David; Thompson, Kristin (2007). El arte cinematográfico: Una introducción. Barcelona: Paidós. ISBN: 97884 49301292

Buckland, Warren (2008). "What does the statistical style analysis of film involve? A review of moving into pictures. More on film history, style, and analysis". Literary and linguistic computing, v. 23, n. 2, pp. 219-230.

https://goo.gl/E7ro4g

https://doi.org/10.1093/Ilc/fqm046

Cortés, Laura (2012). La influencia de la fotografía cinematográfica en el estilo visual. Análisis del estilo de Dick Pope en las obras cinematográficos del director Mike Leigh. Tesis doctoral. Murcia: Universidad de Murcia.

http://repositorio.ucam.edu/handle/10952/691

Cutting, James; DeLong, Jordan; Brunik, Kaitlin (2011). "Visual activity in Hollywood film: 1935 to 2005 and beyond. Psychology of aesthetics, creativity, and the arts, v. 5, n. 2, pp. 115-125.

https://goo.gl/2t15s7

https://doi.org/10.1037/a0020995

Deltell, Luis; García-Fernández, Emilio (2013). "La promoción fílmica en el universo digital. Hacia el ocaso de la exhibición cinematográfica en España". Historia y comunicación social, v. 18, pp. 203-217.

https://doi.org/10.5209/rev_HICS.2013.v18.44237

Erice, Víctor (2005). “Cinema dopo il cinema”. Cineforum, n. 448, pp. 65-69.

Flaxton, Terry (2011). "HD aesthetics". Convergence, v. 17, n. 2, pp. 113-123.

https://doi.org/10.1177/1354856510394884

Fussfeld-Cohen, Orit (2014). "The new language of the digital film". Journal of popular film \& television, v. 42, n. 1, pp. 47-58.

https://goo.gl/vRjSXk

https://doi.org/10.1080/01956051.2012.759898

Gray, Simon (2015). "Max intensity". American cinematographer, v. 96, n. 6, pp. 32-49.

Gubbins, Michael (2011). La revolución digital: El público se implica: Un informe de cine-regio en colaboración con Filmby Aarhus. Arhus: Cine-Regio.

https://goo.gl/CVaUSM
Holben, Jay (2015). "Making monsters". American cinematographer, v. 96, n. 7, pp. 44-53.

Keating, Patrick (2014). Cinematography. New Jersey: Rutgers University Press. ISBN: 081356350X

King, Neal (1999). Heroes in hard times. Cop action movies in the U.S. New Brunswick: Rutgers University Press. ISBN: 9781566397025

Llinàs-Mascaró, Francesc (1989). Directores de fotografía del cine español. Madrid: Filmoteca Española. Centro de Arte Reina Sofía. ISBN: 9788486877026

Loiseleux, Jacques (2005). La luz en el cine. Barcelona: Paidós. ISBN: 9788449317439

Manovich, Lev (2005). El lenguaje de los nuevos medios de comunicación: la imagen en la era digital. Barcelona: Paidós. ISBN: 9788449317699

McGowan, Nadia (2016). "Light creators: the cinematographer's status as an author". En: Caldevilla, David. Nuevas formas de expresión en comunicación. McGraw-Hill Educación, pp. 286-295. ISBN: 9788448612559 https://goo.gl/N5G1Uo

Méndez-Anchuste, Carlos (2016). El ciclo de acción de Hollywood (1980-2015): industria, autoría y cine de acción en la obra de Steven Seagal. Madrid: Tesis inédita. Universidad Complutense de Madrid.

http://eprints.ucm.es/38115

Peiró, Patricia (2013). "Ya no hay rollo en Madrid". El país, 8 junio.

https://goo.gl/Mcv1g8

Prince, Stephen (2004). "The emergence of filmic artifacts: Cinema and cinematography in the digital era". Film quarterly, v. 57, n. 3, pp. 24-33.

https://goo.gl/WzKL22

https://doi.org/10.1525/fq.2004.57.3.24

Quintana, Àngel (2011). Después del cine. Imagen y realidad en la era digital. Barcelona: Acantilado. ISBN: 9788415277484

Revault, Fabrice (2003). La luz en el cine. Madrid: Cátedra. ISBN: 9788437620770

Salt, Barry (1974). "Statistical style analysis of motion pictures". Film quarterly, v. 28, n. 1, pp. 13-22.

https://goo.gl/Aba9rc

https://doi.org/10.2307/1211438

Schneider, Caroline A.; Rasband, Wayne S.; Eliceiri, Kevin (2012). "NIH image to ImageJ: 25 years of image analysis". Nature methods, v. 9, n. 7, pp. 671-675.

https://dx.doi.org/10.1038/nmeth.2089

Thomson, Patricia (2008). "A body fails, a mind adapts". American cinematographer, v. 89, n. 1, pp. 18-26. 